\title{
Features and risk factors of carotid atherosclerosis in a population with high stroke incidence in China
}

\author{
Yanqiu Zhang ${ }^{1}$, Lingling $\mathrm{Bai}^{2,3}$, Min Shi2,3, Hongyan Lu' ${ }^{2}$, Yanan $\mathrm{Wu}^{2,3}$, Jun $\mathrm{Tu}^{2,3,4}$, \\ Jingxian Ni ${ }^{2,3}$, Jinghua Wang ${ }^{2,3,4,5}$, Li Cao ${ }^{6}$, Ping Lei ${ }^{6}$ and Xianjia Ning ${ }^{2,3,4,5}$ \\ ${ }^{1}$ Department of Neurology, Tianjin Nankai Hospital, Tianjin, China \\ ${ }^{2}$ Department of Neurology, Tianjin Medical University General Hospital, Tianjin, China \\ ${ }^{3}$ Department of Epidemiology, Tianjin Neurological Institute, Tianjin, China \\ 4 Tianjin Neurological Institute, Key Laboratory of Post-Neuroinjury Neuro-Repair and Regeneration in Central Nervous \\ System, Ministry of Education and Tianjin City, Tianjin, China \\ ${ }^{5}$ Center of Clinical Epidemiology, Tianjin Medical University General Hospital, Tianjin, China \\ ${ }^{6}$ Department of Geriatrics, Tianjin Medical University General Hospital, Tianjin, China \\ Correspondence to: Xianjia Ning, email: xjn0906@gmail.com \\ Ping Lei, email: leiping1974@163.com
}

Keywords: carotid intima-media thickness, carotid plaque, atherosclerosis, risk factors, epidemiology

Received: October 24, $2016 \quad$ Accepted: February 06, $2017 \quad$ Published: February 16, 2017

Copyright: Zhang et al. This is an open-access article distributed under the terms of the Creative Commons Attribution License 3.0 (CC BY $3.0)$, which permits unrestricted use, distribution, and reproduction in any medium, provided the original author and source are credited.

\section{ABSTRACT}

Epidemiological studies have reported associations between traditional cardiovascular risk factors and carotid intima-media thickness (CIMT) or carotid plaque. However, definite risk factors at different phases of carotid atherosclerosis remain controversial. We aimed to explore risk factors and characteristics of carotid atherosclerosis at different stages in a low-income population with a high incidence of stroke in China. Between April 2014 and January 2015, we recruited 3789 stroke-free and cardiovascular disease-free residents aged $\geq \mathbf{4 5}$ years. B-mode ultrasonography was performed to measure CIMT and the presence of carotid plaque. Traditional risk factors were compared between the increased CIMT group and normal CIMT group, and between those with and without carotid plaque. A total of 3789 participants were assessed in this study, with a mean age (standard deviation) of 59.92 (9.70) years. The prevalence of increased CIMT and carotid plaque increased with older age and higher education levels. Age, hypertension, diabetes, and high low-density lipoprotein cholesterol levels were risk factors for increased CIMT and carotid plaque. Furthermore, compared to never smoking, passive smoking was positively associated with increased CIMT, with an odds ratio (95\% confidence interval) of 1.26 (1.05, 1.53; $P=0.016)$; high body mass index was an obvious protective factor against carotid plaque, with an odds ratio ( $95 \%$ confidence interval) of $0.97(0.95,0.99 ; P=$ $0.004)$. It is important to identify factors associated with atherosclerosis to prevent cardiovascular disease and stroke and reduce the burden of stroke in this high-risk population.

\section{INTRODUCTION}

Although there was no significant change in the age-standardized incidence of stroke in low-income and middle-income countries between 1990 and 2010, there was a significant reduction in mortality rates both in high- income countries and in low- and middle-income countries [1]. According to 2010 statistics, stroke was the leading cause of death in rural areas and the third leading cause of death in urban areas in China [2]. Our previous studies demonstrated that the age-standardized incidence of first-ever stroke dramatically increased over the past two 
Table 1: Demographic characteristics of all subjects in this study

\begin{tabular}{|c|c|c|c|c|}
\hline Risk factors & Total & Men & Women & $\mathbf{P}$ \\
\hline Total: & $3789(100)$ & $1560(41.2)$ & $2229(58.8)$ & \\
\hline Age, mean(SD), years & $59.92(9.70)$ & $61.13(9.90)$ & $59.07(9.47)$ & $<0.0001$ \\
\hline Age group, $n(\%)$ & & & & $<0.0001$ \\
\hline $45 \sim 54$ years & $1236(32.6)$ & $430(27.6)$ & $806(35.2)$ & \\
\hline $55 \sim 64$ years & $1514(40.0)$ & $632(40.5)$ & $882(39.6)$ & \\
\hline $65 \sim 74$ years & $724(19.1)$ & $338(21.7)$ & $386(17.3)$ & \\
\hline$\geq 75$ years & $315(8.3)$ & $160(10.3)$ & $155(7.0)$ & \\
\hline Education, mean(SD), years & $5.48(6.54)$ & $6.40(3.22)$ & $4.84(3.61)$ & $<0.0001$ \\
\hline Education, $n(\%)$ & & & & $<0.0001$ \\
\hline 0 years & $659(17.4)$ & $137(8.8)$ & $522(23.4)$ & \\
\hline $1 \sim 6$ years & $1694(44.7)$ & $699(44.8)$ & $995(44.6)$ & \\
\hline$>6$ years & $1436(37.9)$ & $724(46.4)$ & $712(31.9)$ & \\
\hline Smoking status, $n(\%)$ & & & & $<0.0001$ \\
\hline Never smoking & $2840(75.0)$ & $664(42.6)$ & $2176(97.6)$ & \\
\hline Ever smoking & $173(4.6)$ & $166(10.6)$ & $7(0.3)$ & \\
\hline Current smoking & $776(20.4)$ & $730(46.8)$ & $46(2.1)$ & \\
\hline Alcohol consumption, $n(\%)$ & & & & $<0.0001$ \\
\hline Never drinking & $3198(84.4)$ & $999(64.0)$ & $2199(98.7)$ & \\
\hline Ever drinking & $49(1.3)$ & $48(3.1)$ & $1(0.0)$ & \\
\hline Current drinking & $542(14.3)$ & $513(32.9)$ & $29(1.3)$ & \\
\hline Hypertension, $n(\%)$ & $2583(68.2)$ & $1111(71.2)$ & $1472(66.0)$ & 0.001 \\
\hline Diabetes, $n(\%)$ & $533(14.1)$ & $216(14.1)$ & $317(14.5)$ & 0.719 \\
\hline Obesity, $n(\%)$ & $888(23.4)$ & $323(20.7)$ & $565(25.3)$ & 0.001 \\
\hline SBP, mean(SD), mmHg & $146.42(22.17)$ & $147.76(21.41)$ & $145.49(22.64)$ & 0.002 \\
\hline DBP, mean(SD), mmHg & $86.81(11.40)$ & $88.50(11.22)$ & $85.62(11.39)$ & $<0.0001$ \\
\hline $\mathrm{BMI}, \operatorname{mean}(\mathrm{SD}), \mathrm{Kg} / \mathrm{m}^{2}$ & $25.57(3.68)$ & $25.20(3.44)$ & $25.82(3.82)$ & $<0.0001$ \\
\hline $\mathrm{FBG}$, mean(SD), mmol/L & $5.92(1.57)$ & $5.91(1.42)$ & $5.93(1.67)$ & 0.660 \\
\hline $\mathrm{TC}$, mean(SD), mmol/L & $4.87(1.09)$ & $4.62(1.00)$ & $5.04(1.11)$ & $<0.0001$ \\
\hline $\mathrm{TG}, \operatorname{mean}(\mathrm{SD}), \mathrm{mmol} / \mathrm{L}$ & $1.76(1.24)$ & $1.61(1.24)$ & $1.87(1.22)$ & $<0.0001$ \\
\hline HDL-C, mean(SD), mmol/L & $1.46(0.46)$ & $1.39(0.43)$ & $1.50(0.48)$ & $<0.0001$ \\
\hline LDL-C, mean(SD), mmol/L & $2.70(1.25)$ & $2.61(1.20)$ & $2.76(1.28)$ & $<0.0001$ \\
\hline
\end{tabular}

Abbreviations: SD, standard deviation; SBP, systolic blood pressure; DBP, diastolic blood pressure; BMI, body mass index; FBG, fasting blood glucose; TC, total cholesterol; TG, triglycerides; HDL-C, high density lipoprotein cholesterol; LDL-C, low density lipoprotein cholesterol. 
decades [3-5]. The prevalence of conventional risk factors was high and significantly increased during the period from 1991 to 2011 in this population $[6,7]$.

Carotid artery atherosclerosis (AS) is a strong predictor for cardiovascular disease (CVD) and ischemic stroke events as a result of both luminal stenosis and plaque rupture [8-12]. Carotid intima-media thickness (CIMT), carotid plaque, and carotid stenosis are markers for carotid AS, and they can reflect different phases of carotid artery AS. Increased CIMT mainly represents the early phase of carotid AS, whereas the presence of carotid plaque and carotid stenosis reflects later and advanced phases of the atherosclerotic process [13-15]. Moreover, carotid plaque was found to be a stronger predictor of stroke risk than stenosis [16]. Epidemiological studies have reported associations between traditional cardiovascular risk factors and CIMT or carotid plaque [11, 17-19]. However, factors related to CIMT and carotid plaque are unknown in China, especially among lowincome populations.

Therefore, in this study, we aimed to explore the risk factors and characteristics of carotid AS at different phases among a low-income population in China with a high incidence of stroke.

\section{RESULTS}

\section{Demographics, lifestyle, and risk factors of the study population}

A total of 3789 residents (mean age, 59.92 years) were assessed in this study. There were more women than men (58.8\% vs. $41.2 \%)$, with mean ages of 61.13 years in men and 59.07 years in women. Men were more likely to be older and have higher educational levels; men also exhibited higher prevalence rates of hypertension, diabetes, current smoking, and alcohol consumption. Moreover, systolic blood pressure (SBP) and diastolic blood pressure (DBP) levels were greater in men than in women, but the levels of total cholesterol (TC), triglycerides (TG), highdensity lipoprotein cholesterol (HDL-C), and low-density lipoprotein cholesterol (LDL-C) were greater in women than in men (all $P<0.0001$; Table 1).

\section{Prevalence of increased CIMT and carotid plaque by demographics, lifestyle, and risk factors}

Table 2 shows that the frequency of increased CIMT tended to be greater in men, older participants, those with higher educational levels, current smokers, those

\section{0 residents aged 45 years and over were qualified in this study in 2014 .}

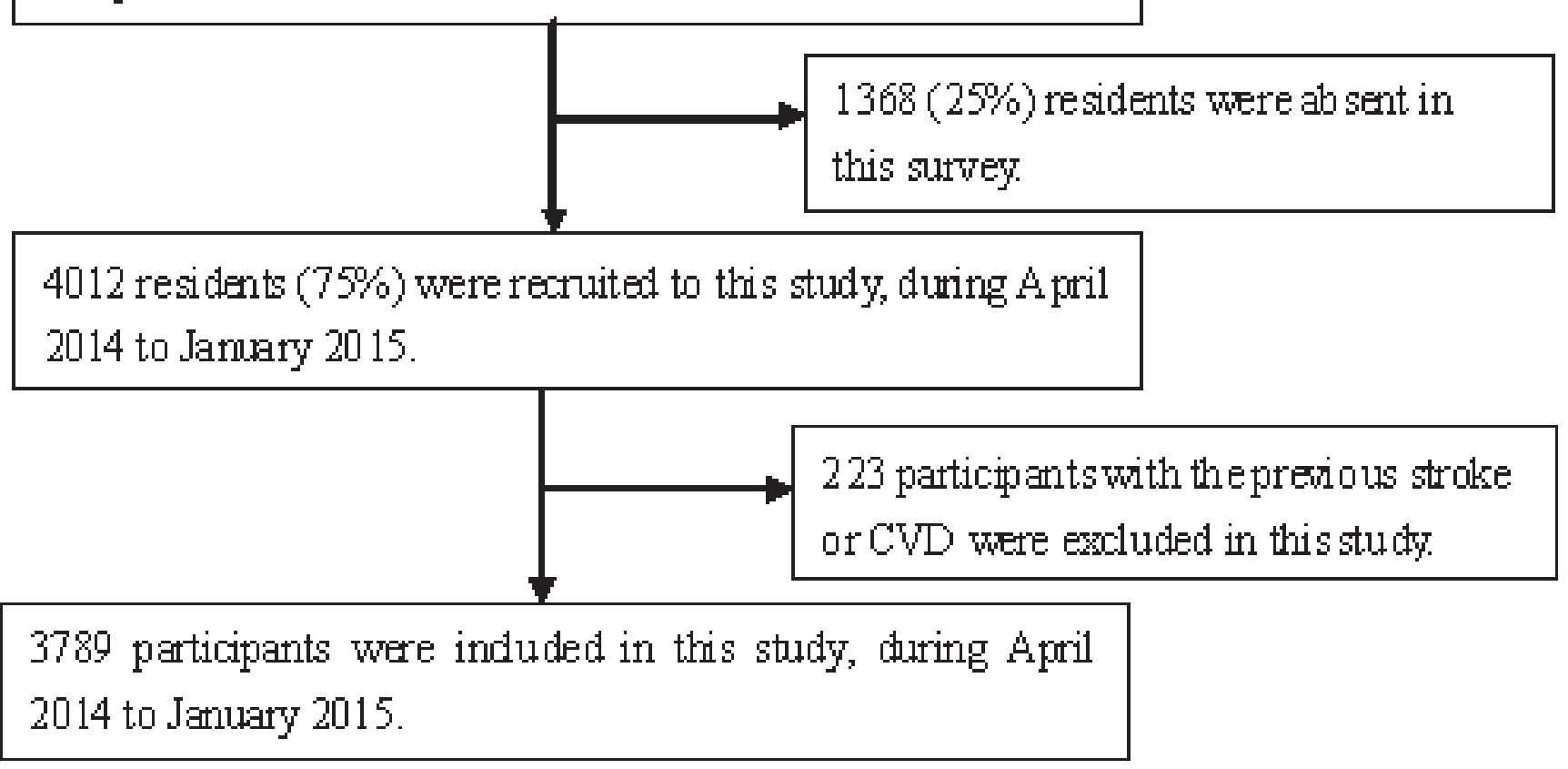

Figure 1: Flow chart of participants 
Table 2: The prevalence of carotid plaque and IMT increased by demographical characteristics and risk factors*

\begin{tabular}{|c|c|c|c|c|}
\hline \multirow{2}{*}{ Risk factors } & \multicolumn{2}{|c|}{ IMT increased } & \multicolumn{2}{|c|}{$\mathbf{C P}$} \\
\hline & Value & $\boldsymbol{P}$ & Value & $P$ \\
\hline Total: & $957(25.3)$ & $<0.001$ & $1574(41.5)$ & $<0.001$ \\
\hline Men & $515(33.0)$ & & $782(50.1)$ & \\
\hline Women & $442(19.8)$ & & $792(35.5)$ & \\
\hline Age group, n (\%) & & $<0.001$ & & $<0.001$ \\
\hline $45 \sim 54$ years & $158(12.8)$ & & $281(22.7)$ & \\
\hline $55 \sim 64$ years & $384(25.4)$ & & $684(45.2)$ & \\
\hline $65 \sim 74$ years & $276(38.1)$ & & $390(53.9)$ & \\
\hline$\geq 75$ years & $139(44.1)$ & & $219(69.5)$ & \\
\hline Education: & & $<0.001$ & & $<0.001$ \\
\hline 0 years & $207(31.4)$ & & $318(48.3)$ & \\
\hline $1 \sim 6$ years & $468(27.6)$ & & $759(44.8)$ & \\
\hline$>6$ years & $282(19.6)$ & & $497(34.6)$ & \\
\hline Smoking status: & & $<0.001$ & & $<0.001$ \\
\hline Never smoking & $493(24.3)$ & & 808 (41.6) & \\
\hline Passive smoking & $253(22.5)$ & & $402(35.8)$ & \\
\hline Ever smoking & $40(27.4)$ & & $66(45.2)$ & \\
\hline Current smoking & $19(33.1)$ & & $298(51.6)$ & \\
\hline Alcohol consumption: & & $<0.001$ & & 0.255 \\
\hline Never drinking & $765(23.9)$ & & $1311(41.0)$ & \\
\hline Ever drinking & $18(36.7)$ & & $31(63.3)$ & \\
\hline Current drinking & $174(32.1)$ & & $232(42.8)$ & \\
\hline Hypertension & & $<0.001$ & & $<0.001$ \\
\hline Yes & $772(29.9)$ & & $1213(47.0)$ & \\
\hline No & $185(15.3)$ & & $361(29.9)$ & \\
\hline Diabetes & & $<0.001$ & & $<0.001$ \\
\hline Yes & $171(32.1)$ & & $282(52.9)$ & \\
\hline No & $765(24.0)$ & & $1263(39.6)$ & \\
\hline BMI & & 0.436 & & 0.002 \\
\hline With IMT increased/CP & $25.49(3.63)$ & & $25.35(3.70)$ & \\
\hline Without IMT increased/CP & $25.59(3.70)$ & & $25.72(3.67)$ & \\
\hline $\mathrm{TC}$ & & 0.038 & & $<0.001$ \\
\hline With IMT increased/CP & $4.93(1.05)$ & & $4.99(1.15)$ & \\
\hline Without IMT increased/CP & $4.84(1.10)$ & & $4.78(1.04)$ & \\
\hline TG & & 0.038 & & 0.903 \\
\hline With IMT increased/CP & $1.69(1.36)$ & & $1.76(1.13)$ & \\
\hline Without IMT increased/CP & $1.78(1.19)$ & & $1.76(1.31)$ & \\
\hline HDL-C & & 0.066 & & 0.582 \\
\hline With IMT increased/CP & $1.43(0.44)$ & & $1.45(0.45)$ & \\
\hline Without IMT increased/CP & $1.46(0.47)$ & & $1.46(0.47)$ & \\
\hline LDL-C & & $<0.001$ & & $<0.001$ \\
\hline With IMT increased/CP & $2.88(1.24)$ & & $3.07(1.44)$ & \\
\hline Without IMT increased/CP & $2.63(1.25)$ & & $2.43(1.02)$ & \\
\hline
\end{tabular}

* all data was presented as rate $(\%)$ with standard error of rate.

TC, total cholesterol; TG, triglycerides; HDL-C, high density lipoprotein cholesterol; LDL-C, low density lipoprotein cholesterol 
Table 3: Description of the load with presence carotid plaques by numbers and total areas of plaques in this population.

\begin{tabular}{|l|c|c|c|}
\hline \multicolumn{1}{|c|}{ Characteristics } & Presence 1 plaque & Presence 2 plaques & Presence $\geq \mathbf{3}$ plaques \\
\hline Total: & & & $178(11.3)$ \\
\hline Cases, $n(\%)$ & $916(58.2)$ & $480(30.5)$ & $62.70(36.42)$ \\
\hline Total plaque areas, $\mathrm{mm}^{2}$ & $11.44(7.96)$ & $28.63(15.73)$ & \\
\hline Without increased CIMT: & & & $84(8.2)$ \\
\hline Cases, $n(\%)$ & $642(63.4)$ & $286(28.3)$ & $55.91(26.57)$ \\
\hline Total plaque areas, $\mathrm{mm}^{2}$ & $10.87(6.94)$ & $26.88(15.18)$ & \\
\hline With increased CIMT: & & & $94(16.7)$ \\
\hline Cases, $n(\%)$ & $274(48.8)$ & $194(34.5)$ & $68.77(42.60)$ \\
\hline Total plaque areas, $\mathrm{mm}^{2}$ & $12.77(9.85)$ & $31.21(16.21)$ & \\
\hline
\end{tabular}

who consumed alcohol, and those with hypertension and diabetes $(P<0.001)$. In the increased CIMT group, TC and LDL-C levels were greater, but TG levels were lower. Similar to increased CIMT, a high prevalence of carotid plaque was found in men, older participants, and those with current smoking status, hypertension, and diabetes; the prevalence of carotid plaque decreased with higher educational levels $(P<0.001)$. TC and LDL-C levels were higher in the carotid plaque group, but a reverse trend was found with body mass index (BMI).

\section{Carotid plaque load by CIMT group}

The prevalence rates of 1,2 , and $\geq 3$ plaques among participants were $58.2 \%, 30.5 \%$, and $11.3 \%$, respectively. The corresponding mean total plaque areas were 11.44 $\mathrm{mm}^{2}, 28.63 \mathrm{~mm}^{2}$, and $62.70 \mathrm{~mm}^{2}$, respectively. In the increased CIMT group, the frequency of $\geq 3$ plaques was $16.7 \%$, and the mean total plaque area was $68.77 \mathrm{~mm}^{2}$ (Table 3).

\section{Risk factors of increased CIMT and carotid plaque}

The multivariate analysis results indicated that male sex, older age, lower education level, hypertension, diabetes, passive smoking, and high LDL-C level were independent risk factors of increased CIMT. The odd ratios with $95 \%$ confidence intervals (ORs [95\% CIs]) were $1.94(1.59,2.37)$ for men compared to women; $1.94(1.55,2.41)$ for age $55-64$ years, $3.22(2.49,4.16)$ for age $65-74$ years, and $4.03(2.91,5.57)$ for age $\geq 75$ years compared to age $45-54$ years; $1.85(1.52,2.24)$ for hypertension compared to non-hypertension; 1.26 (1.02, $1.55)$ for diabetes compared to non-diabetes; 1.26 (1.05, 1.53) for passive smoking compared to never smoking, and $1.15(1.08,1.22)$ for LDL-C level increased by 1 $\mathrm{mmol} / \mathrm{L}$ (Table 4).
Compared to their references, the prevalence of carotid plaque was increased by $76 \%$ in men; 1.44 -fold in those aged 55-64 years, 2.07-fold in those aged 6574 years, and 5.39 -fold in those aged $\geq 75$ years; $56 \%$ in those with hypertension; $50 \%$ in those with diabetes; and $61 \%$ for $1 \mathrm{mmol} / \mathrm{L}$-increase in LDL-C level. However, carotid plaque prevalence decreased by $3 \%$ for each $1 \mathrm{~kg} /$ $\mathrm{m}^{2}$-increase in BMI (all $P<0.0001$; Table 4).

\section{DISCUSSION}

This is the first study to evaluate the characteristics of AS based on increased CIMT and carotid plaque in a low-income population in China. Older age, male sex, lower education level, hypertension, diabetes, passive smoking, and high LDL-C level were independent risk factors of early AS. Simultaneously, we found that carotid AS was associated with age, sex, hypertension, diabetes, BMI, and LDL-C level; of these, high BMI was found to be a protective factor, while the remaining variables were all independent risk factors.

CIMT, which may be measured noninvasively by high-resolution ultrasound imaging, has been widely used as an intermediate marker for AS [20]. CIMT has been found to be a biomarker that may reflect the degree of AS [20, 21]. Previous large-scale follow-up studies have shown that elevated CIMT predicts future vascular events independently of conventional vascular risk factors [2128].

Age and male sex are established risk factors that were significantly associated with increased CIMT [2931]. Consistent with previous studies, we found that CIMT increased along with age, and there was a higher frequency of increased CIMT in male individuals in this study.

Hypertension, diabetes mellitus, dyslipidemia, and smoking have been shown to be associated with increased CIMT [30-32]. Dyslipidemia has been established to be a dubious effected factor of AS. The levels of TC, TG, HDL-C, and LDL-C were significantly associated with 
Table 4: Multivariate analysis for the risk factors of increased CIMT in this study

\begin{tabular}{|c|c|c|c|}
\hline Risk factors & References & OR (95\% CI) & $\boldsymbol{P}$ \\
\hline Men & Women & $1.94(1.59,2.37)$ & $<0.001$ \\
\hline Age groups, $n(\%)$ & $45 \sim 54$ years & & \\
\hline $55 \sim 64$ years & & $1.94(1.55,2.41)$ & $<0.001$ \\
\hline $65 \sim 74$ years & & $3.22(2.49,4.16)$ & $<0.001$ \\
\hline$\geq 75$ years & & $4.03(2.91,5.57)$ & $<0.001$ \\
\hline Education, $n(\%)$ & $>6$ years & & \\
\hline 0 years & & $1.30(1.00,1.68)$ & 0.048 \\
\hline $1 \sim 6$ years & & $1.16(0.96,1.41)$ & 0.136 \\
\hline Hypertension & No & $1.85(1.52,2.24)$ & $<0.001$ \\
\hline Diabetes & No & $1.26(1.02,1.55)$ & 0.033 \\
\hline Smoking status, $n(\%)$ & Never smoking & & \\
\hline Passive smoking & & $1.26(1.05,1.53)$ & 0.016 \\
\hline Ever smoking & & $0.76(0.50,1.16)$ & 0.208 \\
\hline Current smoking & & $1.20(0.94,1.55)$ & 0.145 \\
\hline Alcohol consumption, $n(\%)$ & Never drinking & & \\
\hline Ever drinking & & $1.09(0.86,1.39)$ & 0.468 \\
\hline Current drinking & & $1.21(0.52,1.95)$ & 0.988 \\
\hline LDL-C, mean(SD), mmol/L & - & $1.15(1.08,1.22)$ & $<0.001$ \\
\hline
\end{tabular}

OR, odds ratio; CI, confidence interval; TC, total cholesterol; TG, triglycerides; HDL-C, high density lipoprotein cholesterol; LDL-C, low density lipoprotein cholesterol.

AS in previous reports, and positive relationships were observed between TC, TG, and LDL-C levels [33, 34]; nevertheless, an inverse trend was found for HDL-C level [34]. However, previous studies revealed that TC, TG, and HDL-C levels did not have a significant effect on CIMT [35], and LDL-C level was reported to have an insignificant effect on CIMT [35-37].

In the present study, hypertension and diabetes were independent predictors of elevated CIMT. LDL-C level had an obvious association with increased CIMT; the prevalence was increased by $15 \%$ per $1 \mathrm{mmol} / \mathrm{L}$-increase in LDL-C, but there was no association with TG and HDL-C levels.

Recent investigations in large population-based studies have detected equally strong inverse associations between socioeconomic status and preclinical AS assessed by noninvasive ultrasound measurements of the carotid arteries. Previous studies have shown that low education, low income, and manual occupations are associated with CIMT or with faster progression of CIMT [38, 39]. In line with these previous studies, we found an inverse association between education level and CIMT in the multivariate analysis; the risk of increased CIMT decreased by $30 \%$ in the illiteracy group compared to the $>6$ years education group. Moreover, we found a significant relationship between passive smoking and increased CIMT.

Similar to CIMT, conventional risk factors have been confirmed to be strong risk factors of carotid plaque in previous studies [40, 41]. Age, sex, hypertension, diabetes, TC, and LDL-C were dominating risk factors for developing carotid plaque. Inconsistent with these studies, a protective effect against carotid plaque was observed with increased BMI; the prevalence rate of carotid plaque decreased by $3 \%$ with each $1 \mathrm{~kg} / \mathrm{m}^{2}$-increase in BMI. In white subjects, increased CIMT has been shown to be strongly associated with increased carotid plaque [42], while data from black populations suggest this may not be the case with reduced carotid plaque and large-vessel AS [43]. Black subjects had significantly greater CIMT and a lower prevalence of carotid plaque than white subjects did, after adjusting for cardiovascular risk factors [42, 44]. The discordance of carotid plaque presence and normal CIMT was also observed in other studies $[45,46]$. Even when CIMT levels are not elevated, more than $30 \%$ of subjects have soft or mixed plaque [47]; of those with CIMT > $1 \mathrm{~mm}$, more than $70 \%$ had soft or mixed plaque [48]. Consistent with these studies, we found an inconsistent 
Table 5: Multivariate analysis for the risk factors of carotid plaque in this study

\begin{tabular}{|l|c|c|c|}
\hline \multicolumn{1}{|c|}{ Risk factors } & References & OR (95\% CI) & $P$ \\
\hline Men & Women & $1.76(1.47,2.11)$ & $<0.001$ \\
\hline Age groups, $n(\%)$ & $45 \sim 54$ years & & \\
\hline $55 \sim 64$ years & & $2.44(2.03,2.95)$ & $<0.001$ \\
\hline $65 \sim 74$ years & & $3.07(2.43,3.89)$ & $<0.001$ \\
\hline$\geq 75$ years & & $6.39(4.61,8.84)$ & $<0.001$ \\
\hline Education, $n(\%)$ & $>6$ years & & \\
\hline 0 years & & $1.00(0.79,1.27)$ & 0.999 \\
\hline $1 \sim 6$ years & & $1.07(0.90,1.27)$ & 0.460 \\
\hline Hypertension & No & $1.56(1.32,1.84)$ & $<0.001$ \\
\hline Diabetes & No & $1.50(1.23,1.84)$ & $<0.001$ \\
\hline Smoking status, $n(\%)$ & Never smoking & & \\
\hline Passive smoking & & $1.00(0.841 .19)$ & 0.992 \\
\hline Ever smoking & & $0.80(0.55,1.17)$ & 0.254 \\
\hline Current smoking & & $1.23(0.98,1.55)$ & 0.079 \\
\hline BMI, mean(SD), Kg/m ${ }^{2}$ & - & $0.97(0.95,0.99)$ & 0.004 \\
\hline LDL-C, mean(SD), mmol/L & - & $1.61(1.51,1.73)$ & $<0.001$ \\
\hline
\end{tabular}

OR, odds ratio; CI, confidence interval; BMI, body mass index; LDL-C, low density lipoprotein cholesterol.

trend between CIMT and carotid plaque, namely an increased prevalence of carotid plaque and lower mean value of CIMT in this low-income Chinese population. This paradoxical phenomenon can explain in part the high incidence of first-ever stroke in this population.

A report from the Young Finns Study indicated that offspring exposed to parental smoking in childhood had approximately twice the risk of having a carotid AS plaque in adulthood than did those with nonsmoking parents [49]. Carotid IMT in adulthood was greater in those exposed to smoking with both parents than in those whose parents did not smoke [50]. Moreover, in the ARIC study, the larger IMT observed in the nonsmoking group exposed to passive smoking compared with the nonsmoking group not exposed to passive smoking persisted after controlling for diet, physical activity, BMI, alcohol intake, education, and major cardiovascular risk factors [51]. Consistent with the ARIC study, we found that passive smoking was positively associated with increased CIMT in this study, but not with the presence of carotid plaque. The association may be explained by the activation of platelets leading to their recruitment, adherence, and migration to the endothelium [52]; increased oxidative stress resulting in endothelial dysfunction [53]; greater levels of inflammatory markers such as C-reactive protein and oxidized LDL-cholesterol [54]; a weakening of serum antioxidant defense; accelerated lipid peroxidation; and accumulation of LDL-cholesterol in macrophages [55] and reduced levels of HDL-cholesterol [56]. Additional follow-up studies focusing on the progress of carotid plaque are thus needed.

We acknowledge the limitations of this study. First, the study was conducted in a low-income population from a local town in Tianjin, China, and the results may not be representative of the general population. Second, the cross-sectional study design may have led to a selection bias, especially among healthy elderly subjects. However, including only participants with no history of stroke or CVD may have overcome this limitation. Third, there was no information related to grading of carotid AS, and this may have affected the analysis of carotid AS. Moreover, all participants with carotid plaque were asymptomatic. This may have decreased the selection bias. Finally, information regarding medications and measurements of plasma C-reactive protein and homocysteine were absent in the baseline survey, and therefore, we could not assess the relationship between these variables and AS in this study.

In this cross-sectional study, we assessed the prevalence and relevant risk factors of increased CIMT and carotid plaque among participants aged 45 years and over. There was a lower mean CIMT and higher 
prevalence of carotid plaque in this study across age and gender. Age, sex, hypertension, diabetes, and LDL-C level were significantly associated with CIMT and carotid plaque, but elevated BMI and TC level were protective factors against developing carotid plaque. Therefore, it is vital to identify the factors of AS at different stages to prevent CVD and stroke and to reduce the burden of stroke in this high-risk population.

\section{MATERIALS AND METHODS}

\section{Study population}

This was a population-based cross-sectional study conducted from April 2014 to January 2015.The study population was from the Tianjin Brain Study [4-6]. The study design was described in a previous study [57]. All residents aged 45 years and older with no history of CVD and stroke were recruited in this study, while those with a history of CVD and stroke were excluded.

All investigative protocols were approved by the ethics committee of Tianjin Medical University General Hospital; the methods were carried out in accordance with the approved guidelines, and informed consent was obtained from all participants.

\section{Epidemiological survey and relevant information}

The surveys were conducted through face-to-face interviews by trained research staff to collect name; sex; date of birth; educational level; previous history of hypertension, diabetes mellitus, stroke, transient ischemia, and coronary heart disease; family history of hypertension, diabetes mellitus, stroke, and coronary heart disease; cigarette smoking ( $\geq 1$ cigarette per day for $\geq 1$ year); and alcohol consumption (drinking alcohol $\geq 1$ time per week for 1 year).

All participants were categorized into four age groups: 45-54 years, 55-64 years, 65-74 years, and $\geq 75$ years. Educational level was categorized into three groups according to educational years: illiteracy (no education), 1-6 years, and $>6$ years. Individual and family medical histories, which included hypertension (defined as selfreported hypertension, $\mathrm{SBP} \geq 140 \mathrm{mmHg}, \mathrm{DBP} \geq 90$ $\mathrm{mmHg}$, or taking antihypertensive medication), diabetes mellitus (defined as self-reported diabetes, fasting plasma glucose $\geq 7.0 \mathrm{mmol} / \mathrm{L}$, or taking antidiabetic medication), stroke, transient ischemic attack, and coronary heart disease, were obtained according to patient self-reporting or previous records. Lifestyle variables included cigarette smoking, passive smoking ( $\geq 1$ hour/day or exposed to environmental smoking), and alcohol consumption.

\section{Physical measurements}

Physical examinations with measurements of blood pressure (including SBP and DBP), height, and weight were performed; the levels of fasting blood glucose, TC, TG, HDL-C, and LDL-C in serum were measured. BMI was calculated as weight $(\mathrm{kg})$ divided by the square of height $\left(\mathrm{m}^{2}\right)$.

\section{Ultrasonography measurements}

One trained technician blinded to individuals' previous disease histories performed all ultrasound exams using B-mode ultrasonography (Terason 3000; Burlington, MA, US) with a 5-12 MHz linear array transducer. The CIMT of the far wall of the distal common carotid artery (CCA) was measured as the distance from the leading side of the first echogenic line (lumen-intima interface) to the leading side of the second line (media-adventitia interface). Extracranial carotid artery trees, which included the CCA, the bifurcation, and the internal and external carotid arteries on both sides, were screened for plaque. Examinations included bilateral observation of the longitudinal and transverse views of the CCA. The trained technician performed the carotid ultrasonography with the participants lying in the supine position with the neck extended in mild lateral rotation. The CIMTs for the near and far walls of the CCA were measured both on the left and right, and three values were obtained, which included the maximum CIMT, minimum CIMT, and average CIMT. Images were obtained and digitally stored according to a standard protocol. All scans were recorded on Vascular Research Tools 6 (MIA, LLC) for subsequent off-line analysis. The inter-observer and intra-observer correlation coefficients ranged from $0.88-0.94$ and $0.80-0.95$ for both sides of the CIMT measurement, respectively.

Carotid plaque was defined as a focal structure encroaching into the arterial lumen by at least $0.5 \mathrm{~mm}$ or $50 \%$ of the surrounding CIMT value, or a thickness of more than $1.5 \mathrm{~mm}$ from the intima-lumen interface to the media adventitia interface [58]. Subjects with carotid plaque were included in the carotid plaque group if they had $\geq 1$ identified lesion, regardless of carotid plaque measurements. Both longitudinal and transverse dynamic images of each plaque were stored. Simultaneously, the numbers of carotid plaques and total plaque areas were obtained from each participant with plaque.

All participants were screened by ultrasonographical measurements between April 2014 and July 2014, and all records were analyzed between August 2014 and January 2015 . 


\section{AS staging}

Increased CIMT was defined as an average CIMT of more than $0.61 \mathrm{~mm}$, which was identified based on the greatest quartile $(<0.51,0.51 \sim, 0.5525 \sim$, and $\geq 0.61 \mathrm{~mm})$. The earlier phase of AS was defined based on the presence of increased CIMT, and the advanced stage of AS was defined based on the presence of carotid plaque.

\section{Statistical analyses}

All subjects were categorized into two groups: the early AS group and advanced AS group. Continuous variables are presented as means and standard deviations and were compared between groups using the Student's $t$-test. Categorical variables are presented as numbers with frequencies and were compared using chi-square tests or chi-square trend tests. The risk factors of early AS and advanced AS were assessed individually using logistic regression analyses. Factors of early AS were assessed among those without carotid plaque. The univariate analysis results are presented as unadjusted ORs and 95\% CIs; the multivariate analysis results are presented as adjusted ORs and $95 \%$ CIs after adjusting for covariates. $P$ values $<0.05$ were considered statistically significant. SPSS for Windows (version 13.0; SPSS Inc., Chicago, IL, USA) was used for analyses.

\section{Abbreviations}

CIMT: carotid intima-media thickness

AS: atherosclerosis

SBP: systolic blood pressure

DBP: diastolic blood pressure

TC: total cholesterol

TG: triglycerides

HDL-C: high-density lipoprotein cholesterol

LDL-C: low-density lipoprotein cholesterol

ORs ( $95 \%$ ): odd ratios

CIs: confidence intervals

BMI: body mass index

CVD: cardiovascular disease.

\section{Author contributions}

$\mathrm{JW}, \mathrm{XN}$, and PL were involved in conception and design, and critical review for this article. JW, XN were involved in data analysis for this article. YZ was involved in manuscript drafting. YZ, LB, MS, HL, YW, JT, JN, $\mathrm{JW}, \mathrm{LC}$, and $\mathrm{XN}$ were involved in data collection, case diagnosis and confirmation for this article. All authors reviewed the manuscript.

\section{ACKNOWLEDGMENTS}

We thank all participants of the Tianjin Brain Study, and local medical care professionals for their valuable contributions; and thank Mr. yueqian Ning for advice on revision of the manuscript.

\section{CONFLICTS OF INTEREST}

There is no conflict of interest.

\section{GRANT SUPPORT}

This study was funded by Tianjin Medical University General Hospital.

\section{REFERENCES}

1. Feigin VL, Forouzanfar MH, Krishnamurthi R, Mensah GA, Connor M, Bennett DA, Moran AE, Sacco RL, Anderson L, Truelsen T, O'Donnell M,Venketasubramanian N, BarkerCollo S, et al. Global and regional burden of stroke during 1990-2010: findings from the Global Burden of Disease Study 2010. Lancet. 2014; 383: 245-54.

2. The Ministry of Health of the People's Republic of China: China Health Statistics Yearbook 2011. Beijing: China Union Medical University Press; 2011.

3. Wang J, Bai L, Shi M, Yang L, An Z, Li B, Zhao W, Gu H, Zhan C1, Tu J, Ning X. Trends in Age of First-Ever Stroke Following Increased Incidence and Life Expectancy in a Low-Income Chinese Population. Stroke. 2016;47:929-35.

4. Wang J, Ning X, Yang L, Tu J, Gu H, Zhan C, Zhang W, Su TC. Sex differences in trends of incidence and mortality of first-ever stroke in rural Tianjin, China, from 1992 to 2012. Stroke. 2014; 45:1626-1631.

5. Wang J, An Z, Li B, Yang L, Tu J, Gu H, Zhan C, Liu B, $\mathrm{Su} \mathrm{TC}$, Ning $\mathrm{X}$. Increasing stroke incidence and prevalence of risk factors in a low-income Chinese Population. Neurology. 2015;84:374-81.

6. Wang J, Ning X, Yang L, Lu H, Tu J, Jin W, Zhang W, $\mathrm{Su}$ TC. Trends of hypertension prevalence, awareness, treatment and control in rural areas of northern China during 1991-2011. J Hum Hypertens. 2014;28:25-31.

7. Ning X, Zhan C, Yang Y, Yang L, Tu J, Gu H, Su TC, Wang J. Secular Trends in Prevalence of Overweight and Obesity among Adults in Rural Tianjin, China from 1991 to 2011: A Population-Based Study. PLOS One. 2014;9:e116019.

8. Cao JJ, Arnold AM, Manolio TA, Polak JF, Psaty BM, Hirsch CH, Kuller LH, Cushman M. Association of carotid artery intima-media thickness, plaques, and C-reactive protein with future cardiovascular disease and all-cause mortality: the Cardiovascular Health Study. Circulation. 2007; 116:32-8. 
9. Lorenz MW, von Kegler S, Steinmetz H, Markus HS, Sitzer M. Carotid intima-media thickening indicates a higher vascular risk across a wide age range: prospective data from the Carotid Atherosclerosis Progression Study (CAPS). Stroke. 2006;37:87-92.

10. van der Meer IM, Bots ML, Hofman A, del Sol AI, van der Kuip DA, Witteman JC. Predictive value of noninvasive measures of atherosclerosis for incident Myo-cardial infarction: the Rotterdam Study. Circulation. 2004;109:1089-94.

11. Kuo F, Gardener H, Dong C, Cabral D, Della-Morte D, Blanton SH, Elkind MS, Sacco RL, Rundek T. Traditional Cardiovascular Risk Factors Explain the Minority of the Variability in Carotid Plaque. Stroke. 2012;43:1755-60.

12. Rundek T, Arif H, Boden-Albala B, Elkind MS, Paik MC, Sacco RL. Carotid plaque, a subclinical precursor of vascular events: the Northern Manhattan study. Neurology. 2008;70: 1200-7.

13. Stary HC, Chandler AB, Dinsmore RE, Fuster V, Glagov S, Insull W Jr, Rosenfeld ME, Schwartz CJ, Wagner WD, Wissler RW. A definition of advanced types of atherosclerotic lesions and a histological classification of atherosclerosis. A report from the Committee on Vascular Lesions of the Council on Arteriosclerosis, American Heart Association. Arterioscler Thromb Vasc Biol. 1995;15:151231.

14. Spence JD. Measurement of intima-media thickness $v s$. carotid plaque: Uses in patient care, genetic research and evaluation of new therapies. Int J Stroke. 2006;1:216-21.

15. Mathiesen EB, Johnsen SH. Ultrasonographic measurements of subclinical carotid atherosclerosis in prediction of ischemic stroke. Acta Neurol Scand. 2009;120:68-72.

16. Iemolo F, Martiniuk A, Steinman DA, Spence JD. Sex Differences in Carotid Plaque and Stenosis. Stroke. 2004;35:477-81.

17. Yang D, Iyer S, Gardener H, Della-Morte D, Crisby M, Dong C, Cheung K, Mora-McLaughlin C, Wright CB, Elkind MS, Sacco RL, Rundek T. Cigarette Smoking and Carotid Plaque Echodensity in the Northern Manhattan Study. Cerebrovasc Dis. 2015;40: 136-43.

18. Ren L, Cai J, Liang J, Li W, Sun Z. Impact of Cardiovascular Risk Factors on Carotid Intima-Media Thickness and Degree of Severity: A Cross-Sectional Study. PLoS ONE. 2015;10: e0144182.

19. Leng XY, Chen XY, Chook P, Xiong L, Lin WH, Liu JY, Tomlinson B, Thomas GN, Lam TH, Lam KS, Cheung BM, Wong KS. Association Between Metabolic Syndrome and Carotid Atherosclerosis: A Community-Based Study in Hong Kong. Metab Syndr Relat Disord. 2013;11:109114.

20. Schmidt MI, Duncan BB, Mill JG, Lotufo PA, Chor D, Barreto SM, Aquino EM, Passos VM, Matos SM, Molina Mdel C, Carvalho MS, Bensenor IM. Cohort Profile:
Longitudinal Study of Adult Health (ELSA-Brasil). Int J Epidemiol. 2015;44:68-75.

21. Onbas O, Kantarci M, Okur A, Bayraktutan U, Edis A, Ceviz N. Carotid intima-media thickness: Is it correlated with stroke side? Acta Neurol Scand. 2005;111: 169-71.

22. Collins TC, Beyth RJ. Process of care and outcomes in peripheral arterial disease. Am J Med Sci. 2003;325:125-34.

23. Bots ML, Sutton-Tyrrell K. Lessons from the past and promises for the future for carotid intima-media thickness. J Am Coll Cardiol. 2012;60:1599-604.

24. van den Oord SC, Sijbrands EJ, ten Kate GL, van Klaveren D, van Domburg RT, van der Steen AF, Schinkel AF. Carotid intima-media thickness for cardiovascular risk assessment: Systematic review and meta-analysis. Atherosclerosis. 2013;228:1-11.

25. Bauer M, Caviezel S, Teynor A, Erbel R, Mahabadi AA, Schmidt-Trucksäss A. Carotid intima-media thickness as a biomarker of subclinical atherosclerosis. Swiss Med Wkly. 2012;142:w13705.

26. Touboul PJ, Grobbee DE, den Ruijter H. Assessment of subclinical atherosclerosis by carotid intima media thickness: Technical issues. Eur J Prev Cardiol. 2012;19:1824.

27. Den Ruijter HM, Peters SA, Anderson TJ, Britton AR, Dekker JM, Eijkemans MJ, Engström G, Evans GW, de Graaf J, Grobbee DE, Hedblad B, Hofman A, Holewijn S, et al. Common carotid intima-media thickness measurements in cardiovascular risk prediction: A meta-analysis. JAMA. 2012;308:796-803.

28. Lorenz MW, Polak JF, Kavousi M, Mathiesen EB, Völzke H, Tuomainen TP, Sander D, Plichart M, Catapano AL, Robertson CM, Kiechl S, Rundek T, Desvarieux M, et al. Carotid intima-media thickness progression to predict cardiovascular events in the general population (the PROGIMT collaborative project): A meta-analysis of individual participant data. Lancet. 2012;379:2053-62.

29. Noda H, Iso H, Yamashita S, Ueno H, Yokode M, Yamada N, Ouchi Y, Defining Vascular Disease (DVD) Research Group. Risk stratification based on metabolic syndrome as well as non- metabolic risk factors in the assessment of carotid atherosclerosis. J Atheroscler Thromb. 2011; 18:504-512.

30. Jarauta E, Mateo-Gallego R, Bea A, Burillo E, Calmarza $\mathrm{P}$, Civeira F. Carotid Intima-Media Thickness in Subjects With No Cardiovascular Risk Factors. Rev Esp Cardiol. 2010; 63:97-102.

31. Jarauta E, Mateo-Gallego R, Bea A, Burillo E, Calmarza $\mathrm{P}$, Civeira F. Carotid Intima-Media Thickness in Subjects With No Cardiovascular Risk Factors. Rev Esp Cardiol. 2010;63:97-102.

32. Santos IS, Bittencourt MS, Oliveira IR, Souza AG, Meireles DP, Rundek T, Foppa M, Bezerra DC, Freire CM, Roelke LH, Carrilho S, Benseñor IM, Lotufo PA. Carotid 
intimaemedia thickness value distributions in The Brazilian Longitudinal Study of Adult Health (ELSA-Brasil). Atherosclerosis. 2014;237:227-35.

33. Su TC, Chien KL, Jeng JS, Chen MF, Hsu HC, Torng PL, Sung FC, Lee YT. Age- and gender-associated determinants of carotid intima-media thickness: a community-based study. J Atheroscler Thromb. 2012;19:872-80.

34. Rossi A, Baldo-Enzi G, Calabro A, Sacchetto A, Pessina AC, Rossi GP. The renin-angiotenzin-aldosterone system and carotid artery disease in mild to moderate primary hypertension. J Hypertens. 2000; 18:140-9.

35. Huang F, Yang Z, Xu B, Bi Y, Xu M, Xu Y, Lu J, Liu Y, Dai M, Zhou W, Wang W, Chen Y. Both serum apolipoprotein B and the apolipoprotein B/apolipoprotein A-I ratio are associated with carotid intima-media thickness. PLoS One. 2013;8:e54628.

36. Koskinen J, Kähönen M, Viikari JS, Taittonen L, Laitinen T, Rönnemaa T, Lehtimäki T, Hutri-Kähönen N, Pietikäinen M, Jokinen E, Helenius H, Mattsson N, Raitakari OT, et al. Conventional Cardiovascular Risk Factors and Metabolic Syndrome in Predicting Carotid Intima-Media Thickness Progression in Young Adults. Circulation. 2009;120: 22936.

37. Rundek T, Blanton SH, Bartels S, Dong C, Raval A, Demmer RT, Cabral D, Elkind MS, Sacco RL, Desvarieux M. Traditional Risk Factors Are Not Major Contributors to the Variance in Carotid Intima-Media Thickness. Stroke. 2013;44:2101-8.

38. Mackey RH, Greenland P, Goff DC Jr, Lloyd-Jones D, Sibley CT, Mora S. High-density lipoprotein cholesterol and particle concentrations, carotid atherosclerosis, and coronary events: MESA (Multi-Ethnic Study of Atherosclerosis). J Am Coll Cardiol. 2012;60:508-16.

39. Tan TY, Lu CH, Lin TK, Liou CW, Chuang YC, Schminke U. Factors associated with gender difference in the intimamedia thickness of the common carotid artery. Clin Radiol. 2009;64:1097-103.

40. Nash SD, Cruickshanks KJ, Klein R, Klein BE, Nieto FJ, Ryff CD, Krantz EM, Shubert CR, Nondahl DM, Acher $\mathrm{CW}$. Socioeconomic status and subclinical atherosclerosis in older adults. Prev Med. 2011;52: 208-12.

41. Deans KA, Bezlyak V, Ford I, Batty GD, Burns H, Cavanagh J, de Groot E, McGinty A, Millar K, Shiels PG, Tannahill C, Velupillai YN, Sattar N, et al. Differences in atherosclerosis according to area level socioeconomic deprivation: cross sectional, population based study. BMJ. 2009; 339: b4170.

42. Lanktree MB, Hegele RA, Schork NJ, Spence JD. Extremes of unexplained variation as a phenotype: an efficient approach for genome-wide association studies of cardiovascular disease. Circ Cardiovasc Genet. 2010;3:21521.

43. Spence JD, Barnett PA, Bulman DE, Hegele RA. An approach to ascertain probands with a non-traditional risk factor for carotid atherosclerosis. Atherosclerosis. 1999;144:429-34.

44. Zureik $M$, Ducimetière $\mathrm{P}$, Touboul PJ, Courbon D, Bonithon-Kopp C, Berr C, Magne C. Common carotid intima-media thickness predicts occurrence of carotid atherosclerotic plaques: longitudinal results from the Aging Vascular Study (EVA) study. Arterioscler Thromb Vasc Biol. 2000;20:1622-9.

45. Li R, Duncan BB, Metcalf PA, Crouse JR 3rd, Sharrett AR, Tyroler HA, Barnes R, Heiss G. B-mode-detected carotid artery plaque in a general population: Atherosclerosis Risk in Communities (ARIC) Study Investigators. Stroke. 1994;25:2377-83.

46. Mackinnon AD, Jerrard-Dunne P, Porteous L, Markus HS. Carotid Intima-Media Thickness is Greater but Carotid Plaque Prevalence is Lower in Black Compared with White Subjects. Am J Neuroradiol. 2010;31:1951-5.

47. Wasserman BA, Sharrett AR, Lai S, Gomes AS, Cushman M, Folsom AR, Bild DE, Kronmal RA, Sinha S, Bluemke DA. Risk factor associations with the presence of a lipid core in carotid plaque of asymptomatic individuals using high resolution MRI: the multi-etnic study of atherosclerosis (MESA). Stroke. 2008;39:329-35.

48. Boulos NM, Gardin JM, Malik S, Postley J, Wong ND. Carotid Plaque Characterization, Stenosis, and IntimaMedia Thickness According to Age and Gender in a Large Registry Cohort. Am J Cardiol. 2016;117:1185-91.

49. West HW, Juonala M, Gall SL, Kähönen M, Laitinen T, Taittonen L, Viikari JS, Raitakari OT, Magnussen CG. Exposure to parental smoking in childhood is associated with increased risk of carotid atheroscleroticplaque in adulthood: the Cardiovascular Risk in Young Finns Study. Circulation. 2015;131:1239-46.

50. Gall S, Huynh QL, Magnussen CG, Juonala M, Viikari JS, Kähönen M, Dwyer T, Raitakari OT, Venn A. Exposure to parental smoking in childhood or adolescence is associated with increased carotid intima-media thickness in young adults: evidence from the Cardiovascular Risk in Young Finns study and the Childhood Determinants of Adult Health Study. Eur Heart J. 2014;35:2484-91.

51. Howard G, Burke GL, Szklo M, Tell GS, Eckfeldt J, Evans $\mathrm{G}$, Heiss G. Active and passive smoking are associated with increased carotid wall thickness. The Atherosclerosis Risk in Communities Study. Arch Intern Med. 1994;154:127782.

52. Rubenstein D, Jesty J, Bluestein D. Differences between mainstream and sidestream cigarette smoke extracts and nicotine in the activation of platelets under static and flow conditions. Circulation. 2004;109:78-83.

53. Howard DJ, Ota RB, Briggs LA, Hampton M, Pritsos CA. Environmental tobacco smokein the workplace induces oxidative stress in employees, including increased production of 8-hydroxy-2'-deoxyguanosine. Cancer 
Epidemiol Biomarkers Prev. 1998;7:141-6.

54. Panagiotakos DB, Pitsavos C, Chrysohoou C, Skoumas J, Masoura C, Toutouzas P, Stefanadis C. Effect of exposure to secondhand smoke on markers of inflammation: the ATTICA study. Am J Med. 2004;116:145-50.

55. Valkonen M, Kuusi T. Passive smoking induces atherogenic changes in low-density lipoprotein. Circulation. 1998;97:2012-6.

56. Ayer JG, Belousova E, Harmer JA, David C, Marks GB, Celermajer DS. Maternal cigarette smoking is associated with reduced high-density lipoprotein cholesterol in healthy 8-year-old children. Eur Heart J. 2011;32:2446-53.

57. Zhan C, Shi M, Yang Y, Pang H, Fei S, Bai L, Liu B, Tu J, Huo Y, Ning X, Zhang Y, Wang J. Prevalence and Risk Factors of Carotid Plaque Among Middle-aged and Elderly Adults in Rural Tianjin, China. Sci Rep. 2016;31: 23870.
58. Touboul PJ, Hennerici MG, Meairs S, Adams H, Amarenco P, Bornstein N, Csiba L, Desvarieux M, Ebrahim S, Hernandez Hernandez R, Jaff M, Kownator S, Naqvi $\mathrm{T}$, et al. Mannheim carotid intima-media thickness and plaque consensus (2004-2006-2011). An update on behalf of the advisory board of the 3rd, 4th and 5th watching the risk symposia, at the 13th, 15th and 20th European Stroke Conferences, Mannheim, Germany, 2004, Brussel, Belgium, 2006, and Hamburg, Germany, 2011. Cerebrovasc Dis. 2012;34: 290-6. 